2009

\title{
Buoy Dynamics in Subsurface Zones
}

Randy Guillen

University of South Florida

Advisors:

Arcadii Grinshpan, Mathematics and Statistics

Scott Campbell, Chemical \& Biomedical Engineering

Problem Suggested By: Elliot Findley

Field of Study for Problem Suggester: Mathematician \& Physicist

Follow this and additional works at: https://digitalcommons.usf.edu/ujmm

Part of the Mathematics Commons

UJMM is an open access journal, free to authors and readers, and relies on your support:

Donate Now

\section{Recommended Citation}

Guillen, Randy (2009) "Buoy Dynamics in Subsurface Zones," Undergraduate Journal of Mathematical Modeling: One + Two: Vol. 1: Iss. 2, Article 5.

DOI: http://dx.doi.org/10.5038/2326-3652.1.2.5

Available at: https://digitalcommons.usf.edu/ujmm/vol1/iss $2 / 5$ 


\title{
Buoy Dynamics in Subsurface Zones
}

\begin{abstract}
The objective of this paper is to find the tension acting on a line that anchors a buoy submerged just beneath the surface of the ocean. Since the problem statement only gives the geometric shapes and dimensions of the buoy, we must use calculus to find its volume and surface area through integration of the volumes and surfaces of revolution formed by the specific parts of the buoy along an axis. The volume and surface area determine the buoyancy force and force of gravity, the two forces acting on the buoy that affect the tension in the line. After calculating this data, we were able to conclude that the tension affecting the line would be approximately $78 \mathrm{kN}$ if the buoy was made of $1 \%$ carbon steel with a thickness of $6.35 \mathrm{~mm}$. This problem is useful in several engineering disciplines.
\end{abstract}

\section{Keywords}

Buoy, Tension, Carbon steel

\section{Creative Commons License}

(c) (i) (3)

This work is licensed under a Creative Commons Attribution-Noncommercial-Share Alike 4.0 License. 


\section{Motivation}

In this paper, we calculate the tension that would affect the line that anchors the buoy to the sea floor. This tension would have to be known when deciding what material to use for the line: if the buoy is not sufficiently massive, the tension may be too great and cause the line to snap. To solve this problem we have to conceptualize the forces acting on the buoy and the line.

\section{Problem Statement}

The buoy illustrated below is to be anchored to the bottom of the bay by a line attached to the base of its egg-shaped bottom. It is constructed from welded sheet metal and has dimensions (in feet) as indicated in the picture. Our goal is to find the tension on the line caused by the buoyancy force of the fully submerged buoy- the top of its dome just below the surface of the (salt) water. The cap on the top is a section of a sphere whose dimensions we will determine. The cylindrical abdomen of the buoy is connected to the cap by a collar-shaped section of a cone. The base is the lower third (by height) of an ellipsoid stood on its end. The major- and minor-axes of the ellipsoid can be deduced from the diagram.
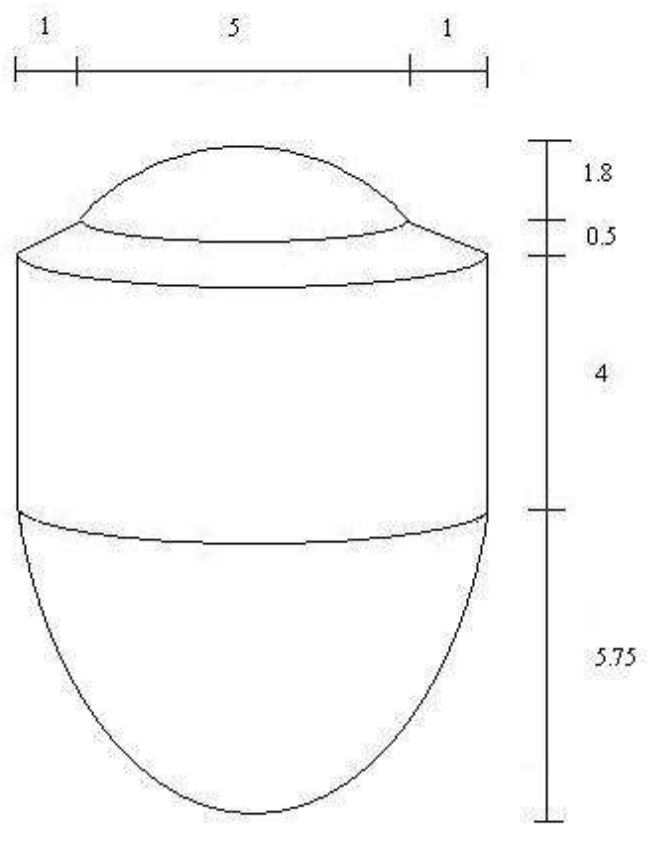

\section{Mathematical Description and Solution Approach}

The first step in this problem was to use geometry and algebra to find the formulas that describe the specific shape of the buoy. The buoy is divided into four parts: a sphere, part of a cone, a cylinder and one third of an ellipse. We have included these calculations in 
the Appendix under Calculations 1,2,3 and 4. We have also included a graph of all the functions together in the Appendix as Picture 2.

The next step was to find the volume and surface area of each shape. The equations used are as follows:

$$
\begin{gathered}
\text { Volume }=\pi \int_{a}^{b} f(x)^{2} d x \\
\text { Surface Area }=2 \pi \int_{a}^{b} f(x) \sqrt{1+f^{\prime}(x)^{2}} d x
\end{gathered}
$$

The Appendix - Calculations 5 through 8 - contains the detailed calculations of each integral. The calculation of the surface area of the sphere actually uses a concept by Archimedes, which states that the surface area of a sphere centered on the $\mathrm{x}$-axis and bounded by the planes $x=a$ and $x=b$ is given by $2 \pi r(b-a)$.

After calculating the volumes and surface areas of each individual shape, we obtained the following results:

$$
\begin{gathered}
\text { total volume } \approx 318.01 \mathrm{ft}^{3} \\
\text { and total surface area } \approx 236.829 \mathrm{ft}^{2}
\end{gathered}
$$

Details are included in Calculation 9 in the Appendix. With this data we could conceptualize the forces acting on the buoy in Picture 3. From this free body diagram we were able to find the tension in the line, which equals the Force of Buoyancy minus the Force of Gravity. We then chose to use $1 \%$ carbon steel - which has a density of $\rho_{\text {Steel }}=7801 \mathrm{~kg} / \mathrm{m}^{3}$ ([1]) —as the designated building material for the buoy and decided the thickness of the sheet steel to be $6.35 \mathrm{~mm}$. Multiplying these two together gives us the surface-area density that we used to calculate the mass of the buoy. These calculations are detailed in the Appendix under Calculation 10. We then plugged in the constant for gravity and the density of salt water, which is $\rho_{\text {Water }}=1013 \mathrm{~kg} / \mathrm{m}^{3}$ (at $20^{\circ} \mathrm{C}$ with a $35 \%$ salinity [2]). With only the tension left unknown, we were able to solve for it. This is also in the Appendix under Calculation 10.

\section{Discussion}

The tension caused by the buoy on the line is approximately $78499.95 \mathrm{~N}$ if the buoy is made of sheet steel with a thickness of $6.35 \mathrm{~mm}$. The resulting tension is quite large, but this make sense since the volume is much larger than the surface area if one multiplies the surface area times the thickness. The results provide a clear guideline when choosing the line to use to anchor the buoy detailed by the design given. 


\section{Conclusions and Recommendations}

The objective of this paper is to find the tension acting on a line holding a buoy submerged just under the surface of the ocean. This required using calculus to find the volume and surface area through integration of the volumes and surfaces of revolution formed by the individual parts composing the buoy. The volume and surface area were necessary to calculate the force of buoyancy and force of gravity, as these are the two forces acting on the buoy that affected the tension in the line. The resulting tension is quite large, which makes sense since the volume is much larger than the surface area. This tension could be used when choosing a line to anchor the buoy. However, the tension would change if the surface area density of the buoy changed.

Our calculations are useful in a variety of contexts. Another approach might involve a different material to build the buoy or a different thickness than what we have chosen here. Another option is to solve for the thickness of a specific material needed to make the tension equal to zero. This would imply that the material would be dense enough to cause the force of gravity to cancel out the force of buoyancy that is caused by the volume of the buoy.

\section{References}

[1] Geankoplis, Christie J. Transport Process and Units Operations. $3^{\text {rd }}$ Ed. Englewood Cliffs: Prentice Hall, 1993.

[2] Thibodeaux, Louis J. Environmental Chemodynamics: Movement of Chemicals in Air, Water, and Soil. $2^{\text {nd }}$ Ed. New York: Wiley-Interscience, 1996. 


\section{Appendix}

Based on the problem statement, we derived formulas to describe the cross section of the buoy as follows:

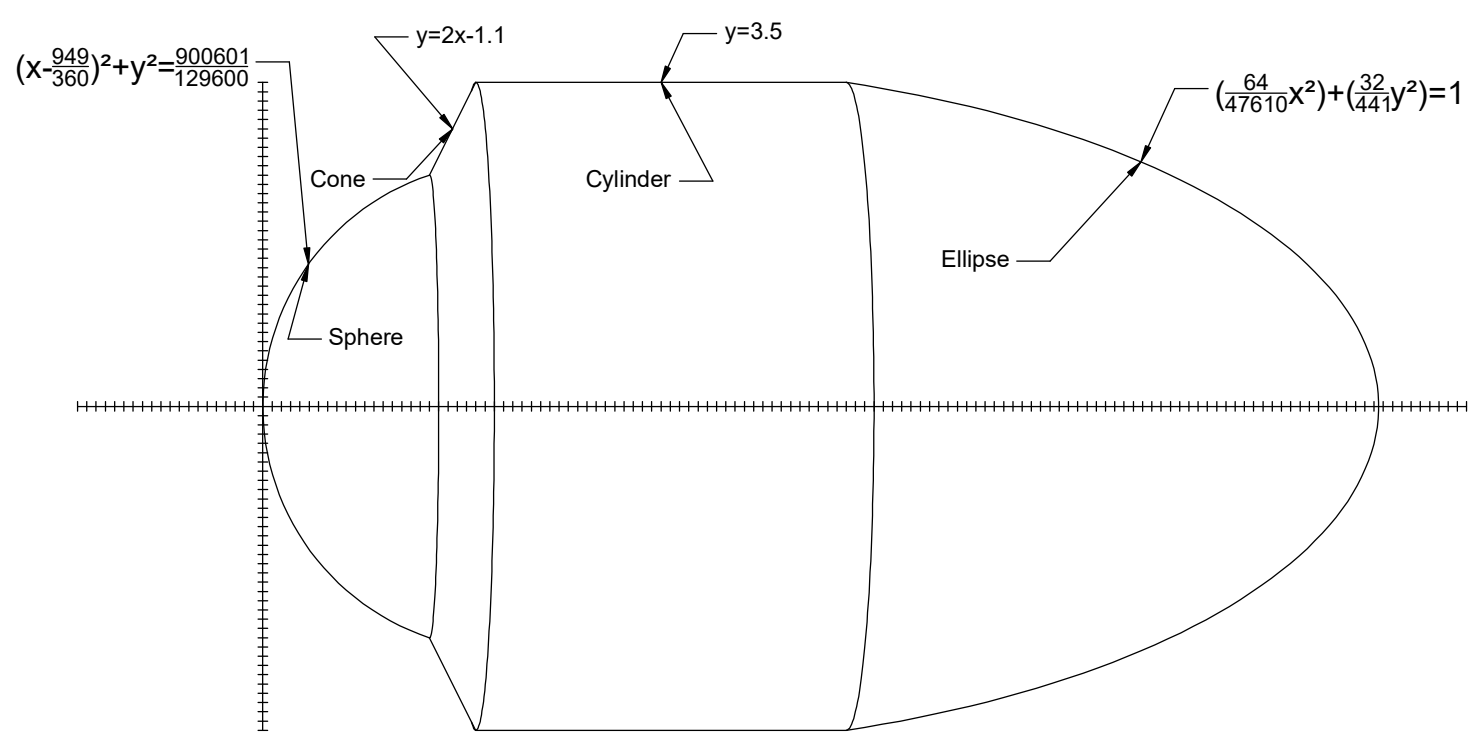

\section{Calculations}
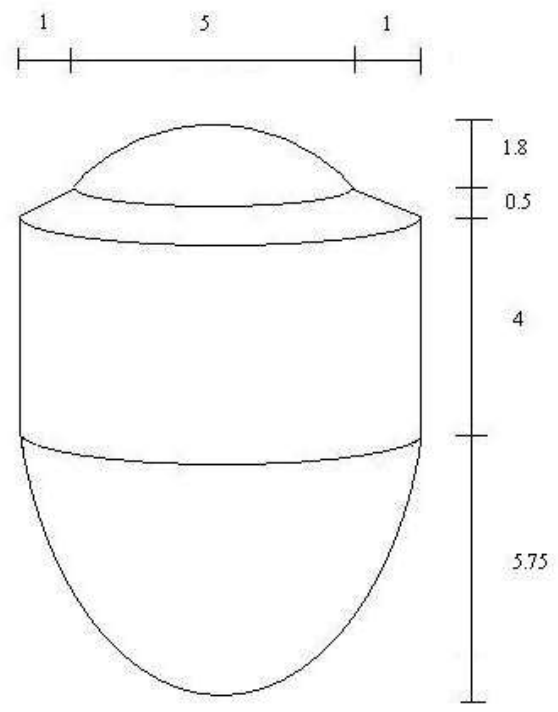


\section{Graph of buoy cross-section}

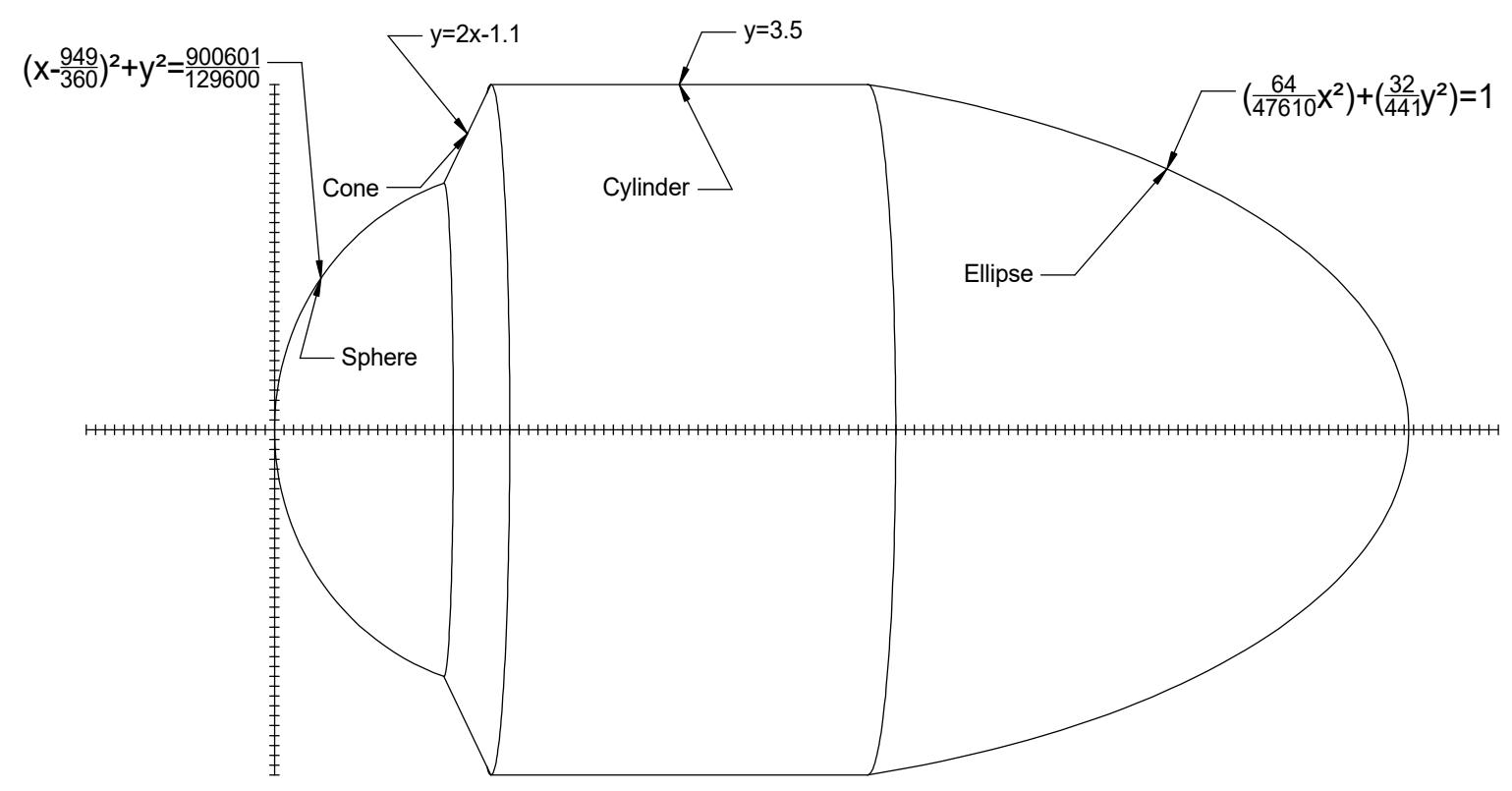

2. Free Body Diagram

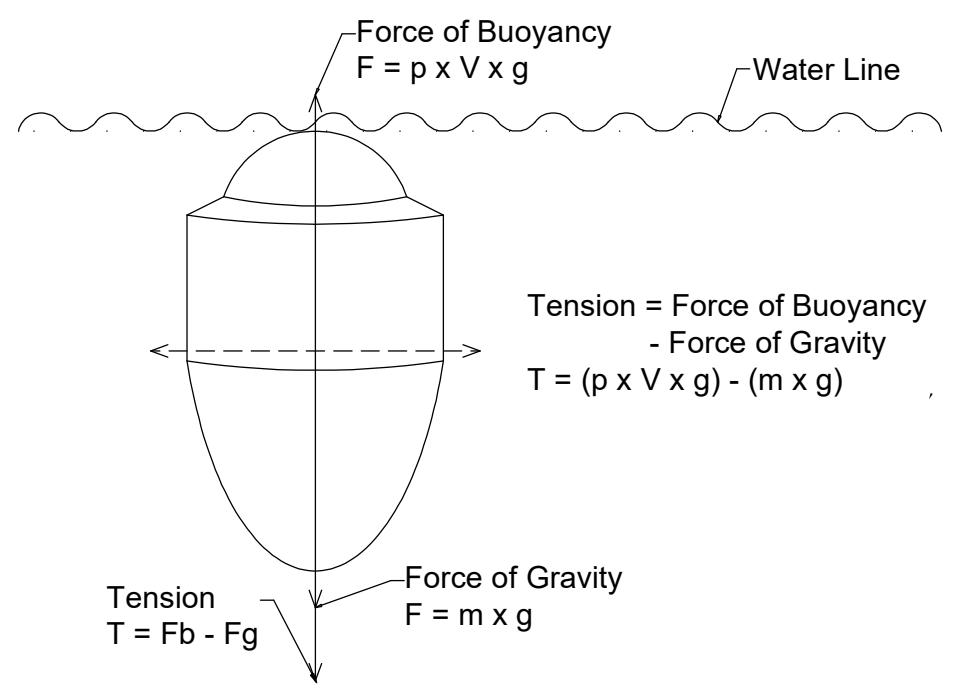




\section{Calculations}

1. Sphere Formula $(x+2.64)^{2}+y^{2}=6.95$

$$
\begin{array}{ccc}
y^{2}=6.95-(x+2.64)^{2} & y=\sqrt{6.95-(x+2.64)^{2}} \\
y=\sqrt{6.95-x^{2}+5.27 x-6.95} & y=\sqrt{-x^{2}+5.27 x} \\
x^{2}+y^{2}=r^{2} & \frac{\mathrm{B}}{\sin \beta}=\frac{\mathrm{A}}{\sin a} & a=\tan \left(\frac{2.5}{1.8}\right)=54.25^{\circ}
\end{array}
$$

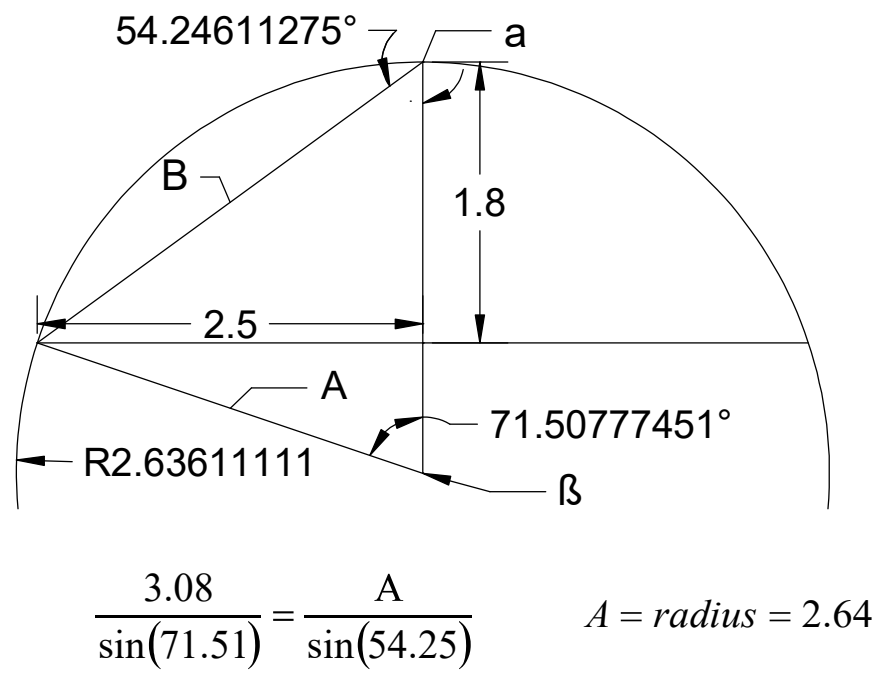

\section{Cone Formula}

slope $=\frac{3.5-2.5}{2.3-1.8}=\frac{1}{0.5}=2 \quad y=m x+b \quad 3.5=(2)(2.3)+b \quad b=3.5-4.6=^{-} 1.1$ 


\section{Cylinder Formula}

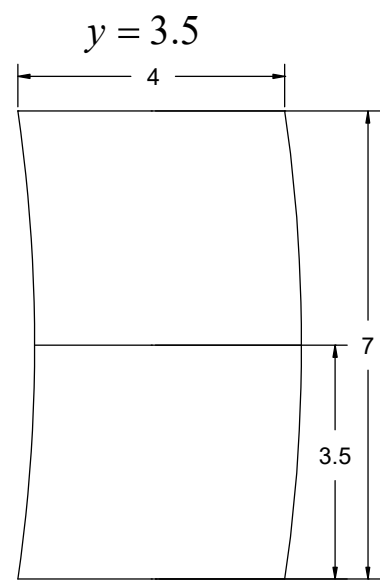

4. Ellipse Formula $\quad 0.013 x^{2}+0.073 y^{2}=1$

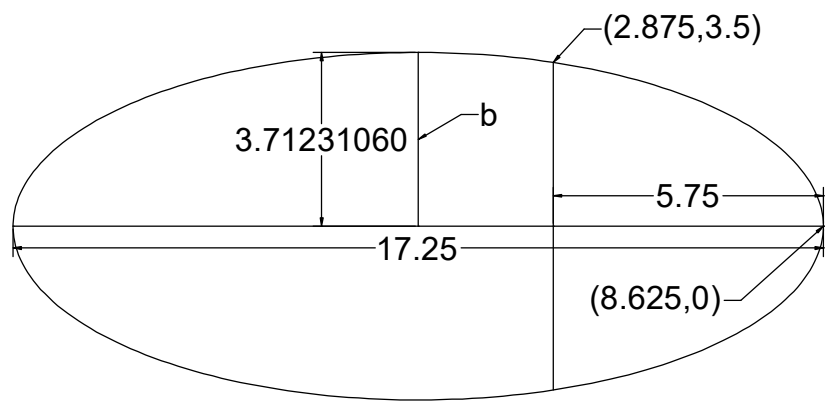

$$
\begin{aligned}
& \frac{x^{2}}{a^{2}}+\frac{y^{2}}{b^{2}}=1 \quad \frac{8.625^{2}}{a^{2}}+\frac{0^{2}}{b^{2}}=1 \quad a=8.625 \\
& \frac{2.875^{2}}{8.625^{2}}+\frac{3.5^{2}}{b^{2}}=1 \quad b=3.71
\end{aligned}
$$

\section{Sphere Integrals}

$$
\begin{gathered}
\text { Volume }=\pi \int_{0}^{1.8}\left(\sqrt{-x^{2}+5.27 x}\right)^{2} d x=\pi \int_{0}^{1.8}\left(-x^{2}+5.27 x\right) d x \\
=\pi\left[-0.33 x^{3}+2.64 x^{2}\right]_{0}^{1.8} \approx 20.72 \mathrm{ft}^{3}
\end{gathered}
$$


From Archimedes, $\quad$ Surface Area $=2 \pi r(b-a)=2 \pi \cdot(2.634) \cdot 1.8$

\section{Cone Integrals}

Volume $=\pi \int_{1.8}^{2.3}(2 x-1.1)^{2} d x=\pi \int_{1.8}^{2.3}\left(4 x^{2}-4.4 x+1.21\right) d x \approx 14.268 \mathrm{ft}^{3}$

Surface Area $=2 \pi \int_{1.8}^{2.3}(2 x-1.1) \sqrt{1+2^{2}} d x=2 \pi \sqrt{5}\left[x^{2}-1.1 x\right]_{1.8}^{2.3} \approx 21.07 \mathrm{ft}^{2}$

\section{Cylinder Integrals}

$$
\begin{gathered}
\text { Volume }=\pi \cdot r^{2} \cdot h=\pi(3.5)^{2} \cdot 4 \approx 153.93 \mathrm{ft}^{3} \\
\text { Surface Area }=2 \pi \cdot r \cdot h=2 \pi(3.5) \cdot 4 \approx 87.96 \mathrm{ft}^{2}
\end{gathered}
$$

\section{Ellipse Integrals}

$$
\begin{array}{r}
\text { Volume }=\pi \int_{2.875}^{8.626}\left[\sqrt{13.78-0.18 x^{2}}\right]^{2} d x \\
=\pi \int_{2.875}^{8.626}\left(13.78-0.18 x^{2}\right) d x \approx 129.7 \mathrm{ft}^{3} \\
\frac{x^{2}}{a^{2}}+\frac{y^{2}}{b^{2}}=1 \Rightarrow 2 y \cdot \frac{y^{\prime}}{b^{2}}=-\frac{2 x}{a^{2}} \Rightarrow\left(y^{\prime}\right)^{2}=\frac{x^{2}}{y^{2}}\left(\frac{b}{a}\right)^{4}
\end{array}
$$

Therefore,

$$
\begin{gathered}
\text { Surface Area }=2 \pi \int_{2.875}^{8.625} y \sqrt{1+\left(y^{\prime}\right)^{2}} d x=2 \pi \int_{2.875}^{8.625} y \sqrt{1+\frac{x^{2}}{y^{2}}\left(\frac{b}{a}\right)^{4}} d x \\
=2 \pi \int_{2.875}^{8.625}\left[y^{2}+x^{2}\left(\frac{b}{a}\right)^{4}\right]^{\frac{1}{2}} d x=2 \pi \int_{2.875}^{8.625}\left[b^{2}\left(1-\frac{x^{2}}{a^{2}}\right)+x^{2}\left(\frac{b}{a}\right)^{4}\right]^{\frac{1}{2}} d x \\
2 \pi \int_{2.875}^{8.625}\left[b^{2}+x^{2}\left(\frac{b^{4}}{a^{4}}-\frac{b^{2}}{a^{2}}\right)\right]^{\frac{1}{2}} d x=2 \pi \int_{2.875}^{8.625} \sqrt{13.76-0.15 x^{2}} d x \\
=2 \pi \int_{2.875}^{8.625} \sqrt{13.76}\left(1-0.011 x^{2}\right)^{\frac{1}{2}} d x
\end{gathered}
$$

Let $u=\sqrt{0.011} x$. Then, 


$$
\begin{gathered}
\text { Surface Area }=2 \pi \sqrt{\frac{13.76}{0.011}} \int_{0.301}^{0.905} \sqrt{1-u^{2}} d u \\
=222.22\left[\frac{1}{2} u \sqrt{1-u^{2}}+\frac{1}{2} \arcsin (u)\right]_{0.301}^{0.905}=102.62 \mathrm{ft}^{2}
\end{gathered}
$$

\section{Total Volume and Surface Area \& Conversions}

Total Volume $=$ Volume $_{\text {sphere }}+$ Volume $_{\text {cone }}+$ Volume $_{\text {cylinder }}+$ Volume $_{\text {ellipse }}$

$$
\approx 20.72 \mathrm{ft}^{3}+14.29 \mathrm{ft}^{3}+153.94 \mathrm{ft}^{3}+129.08 \mathrm{ft}^{3}=318.01 \mathrm{ft}^{3}
$$

Total Surface Area $\approx 29.81 \mathrm{ft}^{2}+21.07 \mathrm{ft}^{2}+87.96 \mathrm{ft}^{2}+102.62 \mathrm{ft}^{2}$

$$
=241.46 \mathrm{ft}^{2}
$$

In metric units,

$$
\begin{gathered}
\text { Total Volume }=9.005 \mathrm{~m}^{3} \\
\text { Total Surface Area }=22.43 \mathrm{~m}^{2}
\end{gathered}
$$

\section{Calculation of the Tension}

$$
\begin{gathered}
\text { Tension = Buoyancy Force }- \text { Weight of Buoy } \\
\text { Bouyancy Force }=(\text { Total Volume }) \times \rho_{\text {water }} \times g \\
=9.005 \times 1013 \mathrm{~kg} / \mathrm{m}^{3} \times 9.81 \mathrm{~m} / \mathrm{s}^{2}=89397.95 \mathrm{~N} \\
\text { Weight of Buoy }=\rho_{\text {steel }} \cdot(\text { Thickness }) \cdot(\text { Total Surface Area }) \cdot g \\
=7801 \mathrm{~kg} / \mathrm{m}^{3} \cdot(0.00635 \mathrm{~m}) \cdot\left(22.43 \mathrm{~m}^{3}\right) \cdot 9.81 \mathrm{~m} / \mathrm{s}^{2}=10898.50 \mathrm{~N}
\end{gathered}
$$

Therefore, the tension on the line is given by

$$
\text { Tension }=89397.95 \mathrm{~N}-10898.50 \mathrm{~N}=78499.95 \mathrm{~N}
$$

